\title{
Perception of Illness and Health Care Among Bhils: A Study of Udaipur District in Southern Rajasthan
}

\author{
Sushila Jain and Seema Agrawal* \\ Department of Sociology, University of Rajasthan, Jaipur, Rajasthan, India \\ *Department of Anthropology, University of Rajasthan, Jaipur, Rajasthan, India
}

\begin{abstract}
KEYWORDS Deities; supernatural powers; Bhopas, physical and mental illness; allopathic doctor
ABSTRACT The study was carried out in two villages namely Madri and Jamun of Jhadol panchayat samiti in Udaipur district of southern Rajasthan. It focuses on perception of illness and health ideology among Bhils. They describe multi- cause for a single illness. They believe that most of the diseases are caused by supernatural powers. Their mode of treatment includes both indigenous and allopathic health care system. Their belief in multi- causational theory regarding occurrence of physical and mental discomfort, past experience, faith and other socio- cultural direct them that as and when, which system should be used.
\end{abstract}

\section{INTRODUCTION}

Every society has its own beliefs and practices regarding health and disease. Perception of illness, customs and practices direct health seeking behaviour of the community. Sociocultural pattern of the community is one of the major factors towards the availability and use of different kinds of treatment. Health and disease are related to sociological and cultural resources of a community in a specific environment (Hassan, 1964). Banerjee and Jalota (1988) in the study of disease and health ideology among Dhimars of Mandla district described that health and disease are not exclusive domain of professional medicine and the treatment for many physical ailments has social and cultural dimensions. Present work focuses on illness and health ideology among Bhils in Southern Rajasthan. Rajsthan's health status is far from satisfactory and it is worse in case of tribals.

It is an empirical study revealing the facts like; Is perception of illness still dominated by magico- religious thoughts among Bhils? What are the factors believed to be responsible for the condition of physical and mental discomfort? What modern health care facilities are available to the Bhils? Which system (indigenous or modern one) is preferred to cure such problems?

\section{MATERIAL AND METHODS}

Two villages namely Madri and Jamun of Jhadol tehsil in Udaipur district are selected to carry out the study on the basis of random sampling technique. Village Madri had a Primary Health Centre (PHC), an Ayurvedic center, a primary and a secondary school, connectivity by pucca road with other villages, electricity, a post office, a bus stand and a well developed market whereas, Jamun lacks aforesaid basic civic amenities except a primary school. 96 Bhil households of village Madri and 60 tribal households from village Jamun have been selected as the sample size. Three variables viz. age, religious sect and educational status of the respondents have been taken into account to conduct the present study.

Observation, interview with the help of interview schedule, interview guide, group discussion (GD), and key informant are used to collect first hand information.

\section{DISCUSSION AND ANALYSIS}

From cradle to the grave, Bhils in both villages feel surrounded by evil spirits and deities of various kinds. They are scared of them because they cause harm and illness. Tribals try to appease them in various ways. Fear and the devotion is the basis of their offerings and worship made to spirits and local deities as well.

Different spirits and deities are allegedly linked with diverse types of diseases. All deities have their own respective departments and areas of influence (Bhasin, 2004:3). Jam, Vishen, Sikotra, Bhut-pret and Churel are some of the malevolent spirits whose annoyance may cause disaster to their lives. Witch is also believed to be a living spirit and as most drastic in nature as compared 
to other spirits. Likewise it is believed that annoyance of the deities also cause the problems. Description of some local deities with their abode place and the problem cured by the respective one is mentioned as below in the table 1 .

Besides, a child is perceived more vulnerable and weak to evil eye effect and hence needs special care to protect it from various diseases. Even grown up persons are believed to be affected by evil eye. In order to ward off the evil eye it is necessary to protect the child from particular individuals who are able to cast evil eye but since it is not always easy to identify these individuals, Bhils resort some practices e.g. practice of tying a black thread around the neck, making a mark with 'Kajal' (lamp black) on forehead and smearing eyes with the same is very common.

Bhil respondents find many factors responsible for causation of a disease. Multi causational
Tribhuwan (1998: 57) observes that disease etiology is an important indigenous medical phenomenon, of any community and precisely stems out from the meaning system (culture). It is clear from the above table that beliefs in supernatural powers still find a prominent place in the occurrence of a physical or mental discomfort. In spite of contact with non tribal world, introduction of new health agencies like allopathic doctor, NGOs, health educators, mass media and spread of formal education Bhils still believe that most of the illnesses are caused by supernatural powers preferably. It is perhaps due to the fact that adaptation to environmental challenges also take the form of cultural responses- the development of particular beliefs and practices to interpret, exploit and respond to the environment (Dennett, and Connel, 1988: 276).

Table 1: Deities and the problems cured

\begin{tabular}{|c|c|c|}
\hline Name of the deity & Abode & Problems cured \\
\hline 1. Avri-Mata & Chittorgarh & paralysis \\
\hline 2. Kali-Mata & Village deity & physical and mental illness \\
\hline 3. Hula-Mata & Jhadol & bestows Children on barren woman when appeased \\
\hline 4. Paba-Baavsi & Paliya Khera & $\begin{array}{l}\text { seasonal illness, miscarriages and also showers her blessings } \\
\text { of a child on Barren woman }\end{array}$ \\
\hline 5. Jaira Mahadev & Madri & Mental and physical discomforts \\
\hline 6. Shandol-Mata & Jhadol & Any physical problem \\
\hline 7. Magra baba & Hill tops & $\begin{array}{l}\text { provides all kinds of protection to Bhils and their crops } \\
\text { from evil spirits }\end{array}$ \\
\hline 8. Ambava Mata & Ambaji & showers her blessings on issueless couples \\
\hline 9. Sitla Mata & Village shrine & small pox and chicken pox \\
\hline 10. Bhanvariyaji Baavsi & Baghpura & mental illness \\
\hline
\end{tabular}

theory is divided into four sub categories. They are as follows:

1) Physical/ biological factors include unnatural change in climate, lightening, lack of fresh air, storms, heavy rains, hereditary and old age etc

2) Supernatural forces are past sins, evil eye, breach of taboos, wrath of deities and evil spirits

3) Socio-cultural factors incorporate contaminated air, unclean water, unbalanced diet, lack of nutritious food, hot and cold food, and laxity in sex.

4) Man-to-Man or man himself include factors like contact with another person suffering from some disease, excessive body weight, unsafe sex and laxity in sex.

To understand the perception of illness among Bhils, table 2 is prepared which exhibits more than one factor responsible for the occurrence of a problem.

Table 2: Multi-causational theory of illnesses as perceived by the Bhils

\begin{tabular}{lcccc}
\hline $\begin{array}{l}\text { Name of } \\
\text { the illness }\end{array}$ & \multicolumn{4}{c}{ Causes } \\
\cline { 2 - 5 } & $\begin{array}{c}\text { Physicall } \\
\text { Biological } \\
\text { factors }\end{array}$ & $\begin{array}{c}\text { Super- } \\
\text { natural } \\
\text { factors }\end{array}$ & $\begin{array}{c}\text { Socio- } \\
\text { cultural } \\
\text { factors }\end{array}$ & $\begin{array}{c}\text { Man-to- } \\
\text { Man/Man } \\
\text { himself }\end{array}$ \\
\hline Tuberculosis & $\sqrt{ }$ & $\sqrt{ }$ & $\sqrt{ }$ & - \\
Cough & $\sqrt{ }$ & - & - & $\sqrt{ }$ \\
Worm- & & & & \\
Infestation & - & $\sqrt{ }$ & $\sqrt{ }$ & - \\
Cholera & - & $\sqrt{ }$ & $\sqrt{ }$ & - \\
Jaundice & - & $\sqrt{ }$ & $\sqrt{ }$ & - \\
Diarrhea & - & $\sqrt{ }$ & - & $\sqrt{ }$ \\
Measles & - & $\sqrt{ }$ & $\sqrt{ }$ & - \\
Guinea & - & - & & \\
-worm & & $\sqrt{ }$ & - & - \\
Fever & $\sqrt{ }$ & $\sqrt{ }$ & $\sqrt{ }$ & $\sqrt{ }$ \\
Pus & - & $\sqrt{ }$ & - & - \\
Chickenpox & $\sqrt{ }$ & $\sqrt{ }$ & - & $\sqrt{ }$ \\
Anemia & $\sqrt{ }$ & $\sqrt{ }$ & - & - \\
Epilepsy & $\sqrt{ }$ & $\sqrt{ }$ & $\sqrt{ }$ & - \\
Diabetes & - & $\sqrt{ }$ & $\sqrt{ }$ & $\sqrt{ }$ \\
STD & - & & & \\
\hline
\end{tabular}




\section{Health Care System}

The treatment of disease in any particular society depends on the world view of the people concerned-it is directly related to the attitude of the general public in respect of looking at the universe (Sarkar, 1993: 330). Help is sought from various types of health care specialists. Allopathic doctor, Bhopa, herbalist and dai are the major specialists available to Bhils to seek help and care of the patient. In fact community, NGOs and state government all play their role so as to provide the Bhil community with a variety of the experts in their fields given as below in brief:

At Community Level: There are various innate curers in Bhil society who are well versed in magico- religious cures, herbal medication, gynecological treatment and bone setting etc. Bhopa, herbalist and dai are some of the important ingredients of traditional health care system. Each one has got a special and significant role in treating and taking care of the patients in their community.

One can find many Bhopas in a village but all of them are not given respect. Only those Bhopas command respects that are well versed in the indigenous pharmacopoeia. It is believed that there are two types of Bhopas. (a) 'Kaccha Bhopa', is a novice who is under training and learning art to become a Bhopa and (b) 'Pucca Bhopa' is a matured and experienced middle-aged man who has learnt the art of Bhopa completely and has cured many patients. There are many Devalos (shrine) near these two villages where Bhopas practice their skill. Two of them are popular among tribals living in the villages Madri and Jamun.

There are two herbalists in village Madri, and only one herbalist in village Jamun. They are practitioners in the art of healing through herbal medicines. A herbalist is wise in Nature's ways (Foster, and Anderson, 1978:104). They get these medicines from the forest and sometimes from general stores of their own or nearby villages. They treat people by their knowledge of healing and are respected and accepted by the villagers whole-heartedly.

The state of becoming a dai (traditional birth attendant) is quite voluntary in the Bhil society. A Dai has full knowledge about the faiths, beliefs and customs existing in their society. So she is more reliable than any other health assistant in the village. In Bhil society dai is like a mother who looks after her daughter, a traditional pediatrician taking care of health and development of infants, a Gynecologist treating gynaec problems and an obstetrician helping a woman in child birth. In Madri and Jamun each there is one-trained traditional dai.

At State Level: A referral hospital i.e. Community Health Center has been established at Jhadol panchayat samiti. As per census report there was no medical health care center in village Madri till 1971. By 1981 a Primary Health Sub-Center had been established at the village Madri, which was further, upgraded to Primary Health Center (PHC) by 1991. This PHC lacks sufficient health personnel, work interest of the staff, adequate supply of medicines, and equipments also. An Ayurvedic hospital was also established there during this period, which generally remains closed for most of the time due to insufficient supply of medicines. There is no Sub Center or Ayurvedic hospital in the village Jamun.

Only one private registered medical practitioner is there in the village Madri who is devoted to his profession and tribals do have faith in him. After seeking home medication and other traditional treatments, tribals consult the private practitioner. If the patient doesn't get cured by him, they move to referral hospital or the private doctor at Jhadol. Serious cases are further referred to the Medical College, Udaipur.

Village Jamun, which lacks any kind of modern health care facility is not easily accessible by Government health personnel as it lacks a pucca road. Moreover, neither ANM nor any health officer contacts them due to the lack of work interest. Therefore, tribals of this village are fully dependent on their indigenous medical system. They rarely go to Udaipur and hardly come in contact with non-tribals.

At $N G O(s)$ Level: A number of NGO's are registered in this region. One of them, Sewa Mandir, plays a vital role in creating basic health care facilities to the Bhils. It provides training to some tribals so as to act as Village Health Guides (Male/ Female) in Madri zone. In the beginning it trained and introduced some tribals as allopathic VHGs in the villages but it was strongly opposed due to its high cost and unsuitability in some of the villages. Hence, in such villages training was given to traditional herbalists, so that they may use their skill in a systematic way.

Total 11 tribal VHGs were working in this area. 
Five of them deal with home medication and rest of them (6) make use of their elementary knowledge about allopathic medicine. It indicates towards increasing popularity of allopathic system in tribal areas.

While working among Nguwasa- Zulu, Ngubane (1977: 101) explained that important decisions, such as consulting a Zulu doctor or diviner or taking the patient to the hospital, are made by the homestead head. Situation is not different among Bhils from what Ngubane had observed. Bhopa, herbalist and an allopathic doctor compete to treat the patient for the same problem by using their specialized skills. But whose skills will be used and when is an important arena to understand their basis of pharmacopoeia. A table of the diseases is given below mentioning the name of the curer according to the preference.

Hence, it is clear that Bhopa is still given top priority to cure physical and mental illness among Bhils (Table 3). Mukherjee (2003:163-164) points out in the study of tribals of Maharashtra that depending on the disease etiology they take certain precautionary measures or treatment. Tribals appear to maintain and retain some sociocultural beliefs and practices with regard to concept of disease, causation and treatment,.... As a matter of fact, multifactorial and multilevel theories of illness etiology permits the use of different treatment resources for different causal factors and levels (Cosminsky, 1977). A question 'whom did they consult during last illness' from the respondents of both villages is asked in this regard. Field data suggest that $68.7 \%$ and $96.67 \%$ respondents in village Madri and Jamun respectively sought the help of traditional healers on

Table 3: Diseases and the curers

\begin{tabular}{lll}
\hline \multicolumn{3}{c}{ Name of the curer } \\
\cline { 2 - 3 } Bhopa & Herbalist & Doctor \\
\hline Dever & Abortion & STD's \\
Headache & Skin boils & Anemia \\
Stomach Pain & Severe Headache Fever \\
Miscarriage & Fever & Cough \\
Diarrhea & Anemia & Severe Diarrhea \\
Z Jaundice & Ear pain & Tuberculosis \\
Dog/ Snake bite & Snake bite & Itching \\
Ulcers & & Allergy \\
Physical Weakness & Leucorrhoea \\
Anemia & & \\
Leucorrhoea & Tuberculosis & \\
Cough & \\
Spirit intrusion &
\end{tabular}

the priority basis. As per analysis and computation of Chi square test age and religious sect of the Bhil respondents were found statistically significant with the preference of the mode of treatment. Educational level of the Bhil respondents has moderate co relation with the preference of the curer.

\section{CONCLUSION}

Age-old cultural values show their profound impact on perception of illness among respondents. Impact of education may be identified as a major factor, which brings some change in their notion. It is not so that all educated respondents hold the scientific view that physical factors, unhygienic food, unclean drinking water, and poor sanitation etc. are the factors responsible for occurrence of the diseases and supernatural powers has a little role to play. But in the above discussion whoever had the idea of the factors for causation of diseases other than supernatural powers they are literate and some of them belong to higher group of education.

Bhasin (2003: 82,83) negates the view of earlier authors like Foster and Anderson (1978) that the traditional and modern medical systems are discrete and bio- medicine will replace traditional medical systems over time. Present study goes well with Bhasin's observation as in Bhil society traditional and bio- medicine co- exist. They are complementary not contradictory to each other. In general, services of indigenous health practitioners are sought in all kind of physical and mental discomforts. It is also revealed that traditional healers do not have $100 \%$ hold over the treatment. Past experiences of Bhils give them an idea about that traditional healer like Bhopa cannot cure all diseases. A herbalist may cure to them but partially. However, frequent relief from the allopathic drugs play a major role in the context of use of modern health care system. Availability and accessibility of allopathic doctor, nature and causes of illness as perceived by Bhils and impact of socio- cultural environment are also some of the important factors to determine that as and when modern health care system should be used.

\section{REFERENCES}

Banerjee, B.G. and Ritula Jalota. 1988. Folk Illness and 
Ethnomedicine. New Delhi. Northern Book Centre. Bhasin, V. 2003. "Sickness and Therapy among Tribals of Rajasthan". Studies of Tribes and Tribals, 1: 82-83.

Bhasin, V. 2004."'Oral Health Behaviour among Bhils of Rajasthan". Journal of Social Science, 8: 3.

Cosminsky, S. 1977. "Impact of methods on the analysis of illness concept in a Guatemala community". Social Science and Medicine, 11: 325.

Dennett, Glenn and John Connel. 1988. "Acculturation and Health in the Highlands of Papua New Guinea". Current Anthropology, 29: 276.

Foster, G.M. and B. Anderson. 1978. Medical Anthropology. New York: John Wiley and Sons.

Hassan, K.A.1964. "The Cultural Frontiers of Health in village India. Bombay". Manak talas cited in Kakkoth, Seetha, 2003. "Health ststus of women in a marginalized tribal community: A study of Arandan of Kerala". Man and Life, 29: 27.

Mukherjee, B.M. 2003. "Cultural aspects of Health in Jowhar of Maharashtra". Studies of Tribes and Tribals, 1: 163-164.

Ngubane, Harriet. 1977. Body and Mind in Zulu Medicine: An Ethnography of Health and Disease in Nguswa-Zulu Thought and Practice. London: Academic Press.

Sarkar, R.M. 1993. "Dimensions of Folk Medicine Traditions in Human Society with special reference to Rural Bengal". Man in India, 73: 330.

Tribhuwan, Robin D. 1998. Medical World of the Tribals: Explorations in Illness Ideology, Body Symbolism and Ritual Healing. New Delhi: Discovery Publishing House. 